\title{
Case Study: A 24-Year-Old Female Got Co-Infection with New Co- rona Virus Pneumonia and Influenza A Virus
}

\author{
Xin Dong ${ }^{1}$, Xiuyun Liu, MD², Xingjia Xie ${ }^{1}$, Longfei Liu ${ }^{3}$, Jun Wang ${ }^{1}$, Peng Xie ${ }^{1}$, Ming Zhang ${ }^{4}$ and \\ Guangbin Jiang $^{1^{*}}$
}

${ }^{1}$ Department of Radiology, Suizhou Hospital, Hubei University of Medicine, China

${ }^{2}$ Department of Anesthesiology \& Critical Care Medicine, School of Medicine, Johns Hopkins University, USA

${ }^{3}$ Xining Pharmaceutical Service Supervision and Management Center of Medical Institution, China

${ }^{4}$ Department of Radiology, Hongshan Hospital, China

*Corresponding author: Guangbin Jiang, Department of Radiology, Suizhou Hospital, Hubei University of Medicine, Hubei, 441300, China, Tel: +86-1772-0270-721

\begin{abstract}
2019 novel coronavirus disease (COVID-19) is a type $\beta$ corona virus that causes severe acute respiratory syndrome. It is highly infectious and has spread widely around the world. Due to the fact that COVID-19 shares similar characteristics with influenza $A$, it is difficult to differentiate COVID-19 from other respiratory viruses at an early stage. In this study, we report a case of a 24-year-old female patient who got co-infection with COVID-19 and influenza A H1N1 in China. The case suggests that COVID-19 might be under diagnosed because of co-infection of other respiratory viruses. Wide viral testing may be necessary for correct diagnosis at the early stage of pneumonia to prevent the spread of the disease and delayed management.
\end{abstract}

\section{Keywords}

COVID-19, Influenza A H1N1, Pneumonia, CT

\section{Introduction}

Since December 2019, there has been an outbreak of novel coronavirus disease (COVID-19) pneumonia around the world. On March $11^{\text {th }}, 2020$, the World Health Organization (WHO) characterized COVID-19 as a pandemic, on the basis of documented human-to-human spread of infection in at least 114 countries. Up to now, more than $1,650,210$ patients were confirmed to be infected with COVID-19 with 100,376 deaths. Countries around the world are adopting different ways to contain the spread of COVID-19. Early detection, pre- vention, and control of COVID-19 is important to protect the health of community and prevent possible spread of coronavirus. However, due to the fact that influenza $A$ share similar characteristics with COVID-19, including fever, cough, and dyspnea, it is difficult to differentiate COVID-19 from other respiratory viruses at an early stage [1]. We report a case of a 24-year-old female who got co-infection with new corona virus pneumonia and influenza A virus subtype H1N1 (H1N1). We want to emphasize that COVID-19 might be under diagnosed because of co-infection of other respiratory viruses and wide viral testing may be necessary for correct diagnosis.

\section{Case Report}

The institutional review board approved this case study and written informed consent was obtained. On January 21, 2020, a 24-year-old female patient, a Wuhan resident, was admitted to the febrile outpatient clinic, Suizhou Affiliated Hospital, Hubei University of Medicine (Hubei, China) with a ten-day history of fever and dry cough. She also presented nonspecific symptoms, such as abdominal pain and diarrhea. Routine blood tests revealed a hemoglobin level of $130 \mathrm{~g} / \mathrm{L}$ (reference range $115-150 \mathrm{~g} / \mathrm{L})$, white blood cell count of $5.2 \times 10^{9} / \mathrm{L}$ (reference range 3.5-9.5 $\times 10^{9} / \mathrm{L}$ ), lymphocyte count of $1.12 \times 10^{9} / \mathrm{L}$ (reference range 1.100-3.200 $\times 109 / \mathrm{L})$, and hypersensitive C-reactive protein of 2.83

Citation: Dong X, Liu X, Xie X, Liu L, Wang J, et al. (2020) Case Study: A 24-Year-Old Female Got CoInfection with New Corona Virus Pneumonia and Influenza A Virus. Int J Radiol Imaging Technol 6:068. doi.org/10.23937/2572-3235.1510068

Accepted: October 17, 2020; Published: October 19, 2020

Copyright: (c) 2020 Dong X, et al. This is an open-access article distributed under the terms of the Creative Commons Attribution License, which permits unrestricted use, distribution, and reproduction in any medium, provided the original author and source are credited 

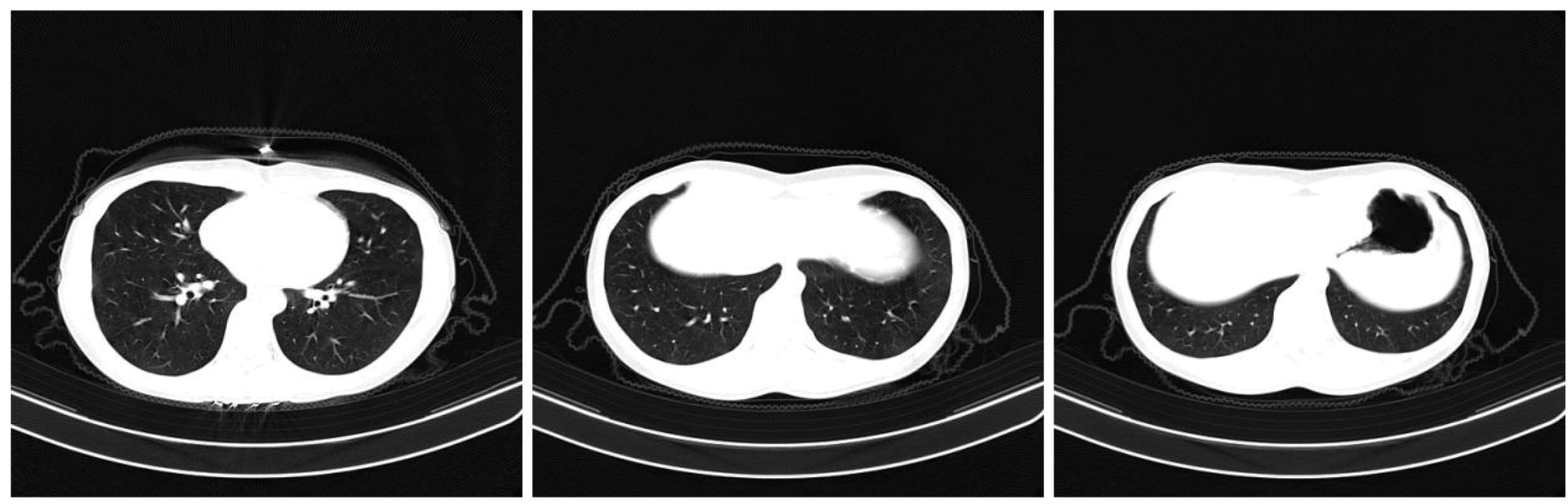

Figure 1: On Jan $21^{\text {st }}, 2010$, CT examination showed no obvious abnormal signs in both lungs. Influenza a virus antigen (positive, + ).
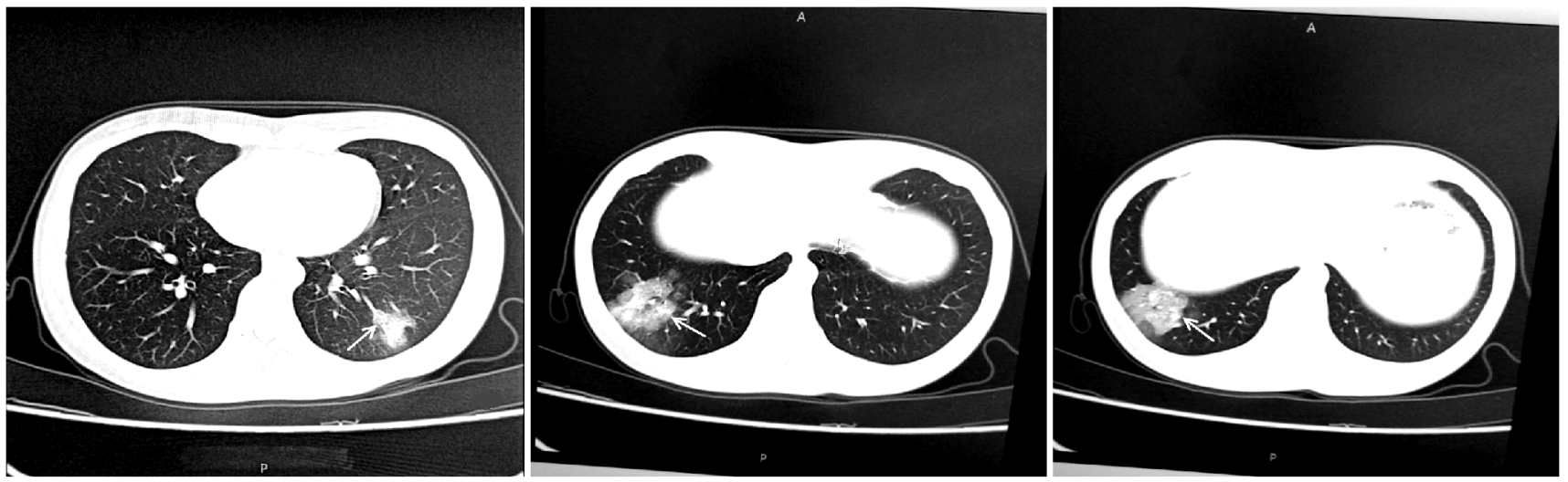

Figure 2: On Jan $26^{\text {th }}, 2020$, a chest radiograph showed patchy ground-glass opacity in the lateral basal segment of the lower lobe of the right lung, vascular thickening in the lesions and a small amount of consolidation (arrows).

$\mathrm{mg} / \mathrm{L}$ (reference range $<5.00 \mathrm{mg} / \mathrm{L}$ ). The percentage of viable neutrophils was $76.31 \%$ (reference range 40.00 $75.00 \%$ ), and the percentage of lymphocyte was $21.60 \%$ (reference range $20.00-50.00 \%$ ). The chest computed tomography (CT) scan revealed no obvious abnormality (Figure 1). Considering her clinical features, we obtained a throat swab specimen and conducted reverse transcription-PCR (RT-PCR) for rapid influenza antigen test by using reagents provided by Bioperfectus Technologies Co., Ltd. (Jiangsu, China). The results showed positive influenza A H1N1 antigen (+) and negative influenza $B$ virus antigen (-). Therefore, the patient was discharged with oral oseltamivir levofloxacin tablets $(0.5$ g, q.d., 7 days) and oseltamivir capsules ( 75 mg, b.i.d., 7 days) as a routine treatment for influenza.

On January $26^{\text {th, }} 2020$, she returned to the hospital due to a new symptom of chest pain. Physical examination revealed a body temperature of $36.7^{\circ} \mathrm{C}$, regular pulse of $78 \mathrm{times} / \mathrm{min}$, regular respiration rate of 19 times/min, and blood pressure of $116 / 73 \mathrm{mmHg}$. A chest radiograph showed patchy ground-glass opacity in the lateral basal segment of the lower lobe of the right lung and vascular thickening in the lesions, indicating acute respiratory distress syndrome (Figure 2). Due to the lim-
Table 1: The result of reverse transcription-PCR for COVID-19.

\begin{tabular}{|l|l|l|l|}
\hline & \multicolumn{3}{|c|}{ Date } \\
\hline Assay & 28-Jan & 5-Feb & 9-Feb \\
\hline Positive & + & & \\
\hline Negative & & - & - \\
\hline
\end{tabular}

Table 2: Routine blood test results.

\begin{tabular}{|l|l|l|l|}
\hline \multirow{2}{*}{ Index } & \multicolumn{3}{|c|}{ Date } \\
\cline { 2 - 4 } 21-Jan & 28-Jan & 3-Feb \\
\hline WBC $(5.2 \times 10 \% / \mathrm{L})$ & 5.2 & 4.8 & 5.7 \\
\hline LYM $\left(1.12 \times 10^{9} / \mathrm{L}\right)$ & 1.12 & 2.13 & 2.31 \\
\hline LYM (\%) & 21.6 & 44.5 & 40.6 \\
\hline NEUT (\%) & 76.31 & 47.4 & 51.4 \\
\hline CRP (mg/L) & 2.83 & $<3.14$ & $<3.14$ \\
\hline Liver and kidney function & normal & normal & normal \\
\hline Troponin (ng/mL) & - & $<0.003$ & $<0.003$ \\
\hline LDH (U/L) & - & 165 & 133 \\
\hline PCT (ng/mL) & - & 0.03 & 0.02 \\
\hline Pulse oxygen saturation (\%) & - & - & 99 \\
\hline
\end{tabular}

WBC: White Blood Cells; LYM: Lymphocytes; NEUT: Neutrophil; CRP: C-Reactive Protein; LDH: Lactic Dehydrogenase; PCT: Procalcitonin. 
ited testing kit, we could not do RT-PCR for COVID-19 on January $26^{\text {th }}$; however, we treated him as a COVID-19 case based on the CT findings. She was admitted to isolation ward and all her close contacts were quarantined. The patient was treated with antiviral therapy (Abidor $200 \mathrm{mg}$, t.i.d; Levofloxacin tablet $0.5 \mathrm{~g}$, q.d.; Mist-interferon atomization $500 \mathrm{IU}$, b.i.d.). On January $28^{\text {th }}$, we obtained a pharyngeal swab specimen and conducted RT-PCR for COVID-19 by using reagents provided by Nanjing Vazyme Biotech Co. Ltd. (Jiangsu, China, http:// www.vazyme.com/Home.html). The nucleic acid test showed positive result for COVID-19 (Table 1). Routine blood tests were performed on January $28^{\text {th }}$ and February $3^{\text {rd }}$ after admission (Table 2). The patient underwent nucleic acid tests and pharyngeal swab, and the results were negative for COVID-19 on Feb $5^{\text {th }}$ and Feb $9^{\text {th }}$. CT examinations were performed on the $11^{\text {th }}$ (Figure 3 ) and $17^{\text {th }}$ day after admission (Figure 4). On day $17^{\text {th }}\left(\right.$ Feb $11^{\text {th }}$, 2020), the patient was discharged and the precautions were taken.

\section{Discussion}

COVID-19 is currently causing big concern in the medical community as the virus is spreading around the world. Early identification plays a pivotal role in the accurate diagnosis, isolation, and treatment for patients infected with COVID-19 [1]. The present case is a radiography-confirmed pneumonia patient with co-infection of COVID-19 and H1N1, and it highlights the challenges in distinguishing COVID-19 from other upper respiratory tract infection (URTI), including influenza virus, adenovirus, respiratory syncytial virus etc., at an early stage. The CT image and the RT-PCR test showed positive result of H1N1 on the first day and we did not do RT-PCR test for COVID-19, thus the patient was discharged with a routine treatment of H1N1. However, the patient got worse after 6 days and returned to the hospital. Due to the limited testing kit, we did a chest CT, which showed enlarged left lung lesions and blood vessels, and increased vessel permeability caused by delayed lung inflammation. The patient was treated as a COVID-19 positive case. Two days later, she was confirmed by RT-PCR test. The case showed the advantage and value of CT scan for COVID-19 diagnosis in extreme situations with limited medical resources. The chest CT imaging is not only the first choice for pneumonia screening and diagnosis but also an essential means of assessing the outcome and treatment of the disease.
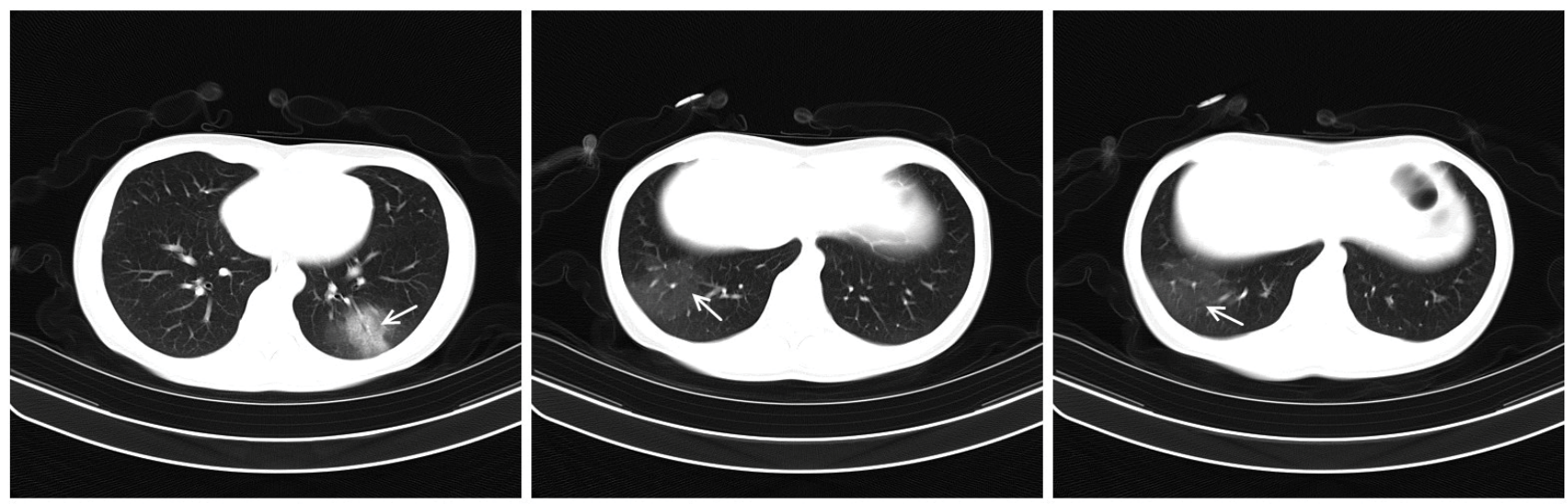

Figure 3: On Feb $5^{\text {th }}, 2020$, the scope of the lesion in the lateral basal segment of the lower lobe of the left lung was enlarged, with surrounding exudation and thickened vascular shadow. The lesion in the lateral segment of the lower lobe of the right lung became lighter (arrows).
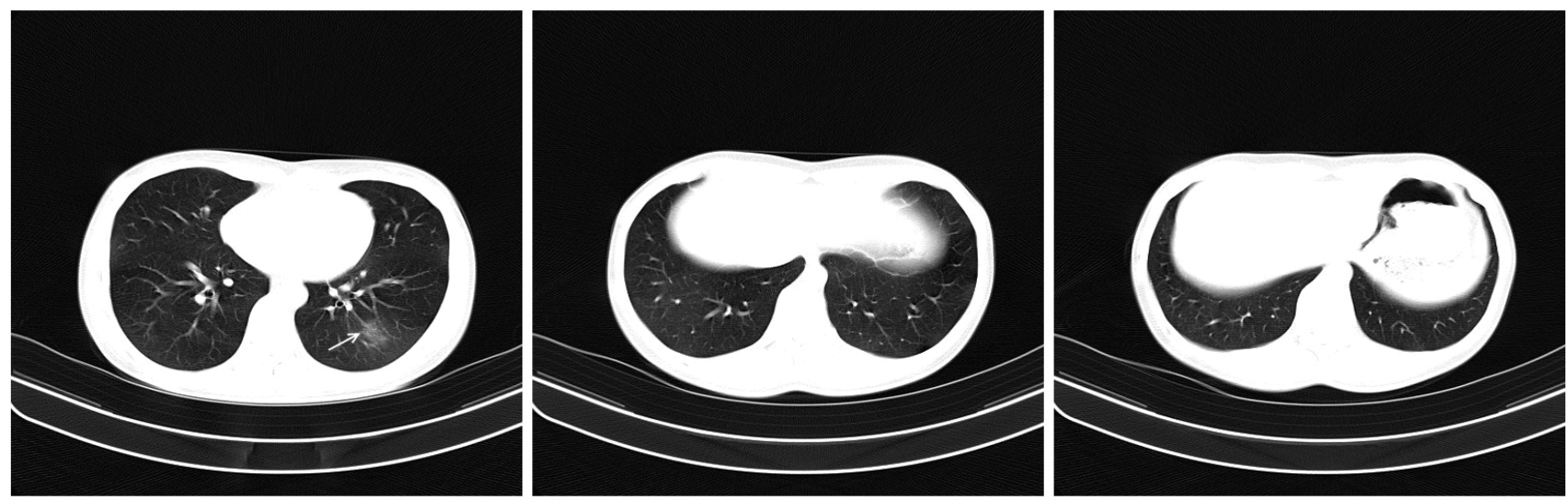

Figure 4: On Feb $11^{\text {th }}, 2020$, the scope of lesions in the lateral basal segment of the lower lobe of the left lung was significantly reduced and diluted. The lesion in the lower lobe of the right lung was basically absorbed. 
Specific characteristics of influenza pneumonia include bilateral reticulonodular areas of opacity at an early stage, or poorly defined patchy or nodular areas of consolidation at a late stage [2-5]. Although CT images of COVID-19 are similar to other viral pneumonia, its specific characteristics including the morphological changes, distribution together with the clinical symptoms and epidemiologic history of the patient, are still of great significance for the diagnosis of COVID-19. Previous studies already indicated that patients with COVID-19 demonstrated more often with ground-glass opacities while patients with H1N1 showed more consolidation [6]. In the present case, after the admission of the patient with correct diagnosis, patient was treated with antiviral therapy by indirect-acting antiviral agent. She recovered after two weeks and was discharged on Feb $11^{\text {th }}$.

In summary, our case suggests that COVID-19 might be under diagnosed because of co-infection of other respiratory viruses. Wide viral testing may be necessary for correct diagnosis at the early stage of pneumonia to avoid delayed management. The case also showed the value of CT scan for COVID-19 diagnosis in extreme situations with limited medical resources.

\section{Sources of Funding}

None.

\section{Disclosures}

None.

\section{References}

1. Wu X, Cai Y, Huang X, Yu X, Zhao L, et al. (2020) Co-infection with SARS-CoV-2 and influenza $A$ virus in patient with pneumonia, China. Emerg Infect Dis 26: 1324-1326.

2. Agarwal PP, Cinti S, Kazerooni EA (2009) Chest radiographic and $C T$ findings in novel swine-origin influenza $A$ (H1N1) virus (S-OIV) infection. AJR Am J Roentgenol 193: 1488-1493.

3. Marchiori E, Zanetti G, D'Ippolito G, Verrastro CGY, Meirelles GSP, et al. (2011) Swine-origin influenza A (H1N1) viral infection: Thoracic findings on CT. AJR Am J Roentgenol 196: W723-W728.

4. Oikonomou A, Muller NL, Nantel S (2003) Radiographic and high-resolution CT findings of influenza virus pneumonia in patients with hematologic malignancies. AJR Am J Roentgenol 181: 507-511.

5. Steel J, Staeheli $P$, Mubareka S, Sastre AG, Palese $P$, et al. (2010) Transmission of pandemic H1N1 influenza virus and impact of prior exposure to seasonal strains or interferon treatment. J Virol 84: 21-26.

6. Tang X, Du R, Wang R, Cao TZ, Guan LL, et al. (2020) Comparison of hospitalized Patients with acute respiratory distress syndrome caused by COVID-19 and H1N1. Chest 158: $195-205$. 